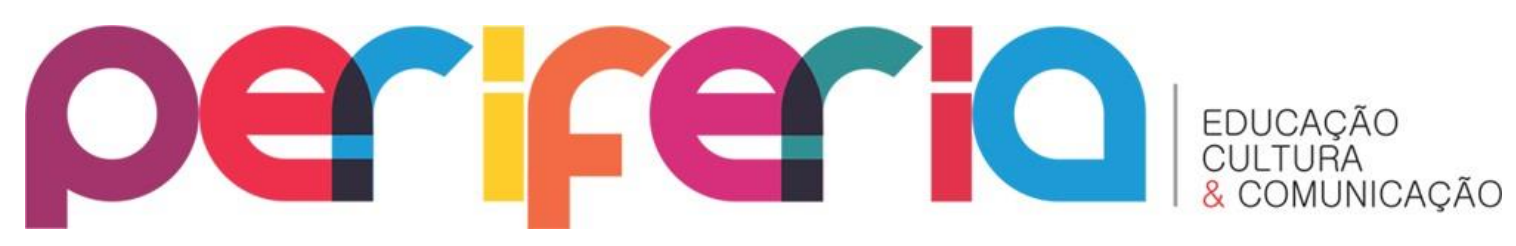

\title{
O PERFIL HISTÓRICO-COGNITIVO DE ALUNOS SURDOS: ENTRE RELATOS EXPERIENCIAIS, EMOCIONAIS E DE APRENDIZAGEM NA FAMÍLIA E NA ESCOLA
}

\author{
Arlete Marinho Gonçalves ${ }^{1}$ \\ Universidade Federal do Pará
}

\section{Resumo}

O estudo objetivou analisar o perfil histórico-cognitivo de pessoas surdas, estudantes universitários, por meio dos relatos vivenciados por eles, na escola, na família e na comunidade. A metodologia adotada foi a pesquisa qualitativa do tipo analítica com cinco surdos, estudantes da universidade Federal do Pará e da Universidade Federal do Oeste do Pará. A técnica utilizada foi o questionário semi-aberto, com o apoio de intérpretes de Libras. Utilizou-se ainda o uso de mapa mental para desenvolver as análises das sinalizações dos sujeitos. Os resultados apontaram para um perfil dos sujeitos surdos construídos por meio de sentimentos (reações, relações, emoções negativas e positivas) e de formas de aprendizagem que se voltaram para o orgulho do uso da Língua de sinais, como identificação de uma cultura surda que percebe ao longo de suas experiências de vida familiar e escolar, que a Libras se manifesta como a melhor opção para o processo de aprendizagem na escola e nas interações entre surdo-surdo e surdo-ouvinte que conhece a língua de sinais. 0 contato com outros surdos e professores fluentes na Libras proporcionou aquisição e aprimoramento da língua de sinas, apontada como sua língua de instrução com aproximações do bilinguismo.

Palavras-chave: aluno surdo; perfil histórico-cognitivo; língua de sinais

\footnotetext{
${ }^{1}$ Doutora em Educação (UFPA). Professora da UFPA de Educação Especial/Inclusiva e Libras. Líder do Grupo de Estudos e Pesquisas em Educação Especial (GEPEE). arletmarinho@gmail.com
} 


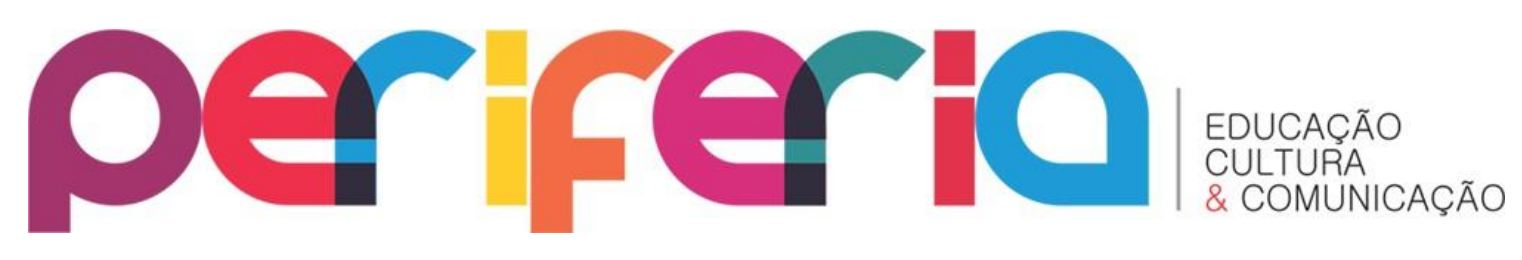

COGNITIVE-HISTORY PROFILE OF DEAF STUDENTS: BETWEEN EXPERIENTIAL, EMOTIONAL STORIES AND LEARNING IN THE FAMILY AND AT SCHOOL

\section{Abstract}

The study aimed to analyze the cognitive-history profile of deaf people, college students, through the reports experienced by them, in school, in the family and in the community. The adopted methodology was qualitative research analytic type with five deaf, students of the Federal University of Pará and the Federal University of the West of Pará. The technique used was semi-open questionnaire, with the support of interpreters. Still was using mind map to develop the analysis of the signals of the subjects. The results pointed to a profile of the deaf built through feelings (reactions, relationships, negative and positive emotions) and forms of learning that have turned to the use of sign language, as identification of a deaf culture that realizes throughout their experiences of school and family life and school, the Pounds manifests itself as the best option for the learning process in school and the interactions between deaf-deaf and deaf listener who knows sign language. Contact with other deaf and teachers fluent in Pounds provided the acquisition and improvement of language of signs, as your language of instruction with approximations of bilingualism.

Keywords: deaf student; profile cognitivehistory; sign language 


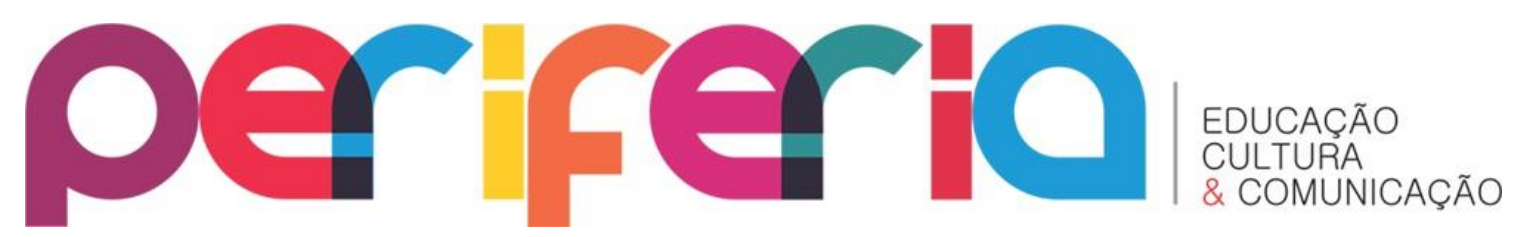

\section{INTRODUÇÃO}

A discussão das diferenças e das identidades culturais ganhou força no início da década de 90, principalmente, com a instauração da "Declaração Mundial de Educação para Todos", realizada em Jontiem, em 1990 e a "Declaração de Salamanca" (1994). Não podemos negar que no final dessa década, do século $X X$, houve maior preocupação política com as práticas inclusivas, dentre elas as ações afirmativas para atender variados grupos culturais excluídos ${ }^{2}$ social e educacionalmente.

Dentre os grupos excluídos, daremos destaque, aqui, às pessoas de cultura surda, usuárias da Língua Brasileira de Sinais. Cultura surda é uma expressão que fizemos opção em utilizar nesta construção por trazer substratos de reflexões, análises e propostas com as quais comungamos relacionadas às pessoas usuárias da Língua de Sinais.

Além disso, as expressões "surdas", "sujeitos surdos" ou "pessoas de Cultura surda" estão sendo largamente utilizadas, nos últimos anos, pelo grupo dos Estudos surdos ${ }^{3}$, fundamentadas pelos Estudos Culturais (EC) e reconhecidas no Decreto $n^{\circ} 5626 / 2005$, quando destaca que a pessoa Surda é aquela que "por ter perda auditiva, compreende e interage com o mundo por meio de experiências visuais, manifestando sua cultura principalmente pelo uso da Língua Brasileira de Sinais" (BRASIL, 2005, grifo nosso).

É necessário compreender que os sujeitos surdos, em especial, os sinalizadores, se comunicam de forma viso-espacial e têm como referência: a configuração das mãos, o ponto de articulação, a orientação, a direção do sinal, e a expressão facial e corporal; diferentemente dos ouvintes, que se comunicam de forma oral-auditiva, e dos deficientes auditivos ${ }^{4}$ com resíduos

\footnotetext{
${ }^{2}$ Considera-se pessoas com deficiência, afrodescendentes, indígenas, crianças vulneráveis, diferenças linguísticas e outros.

${ }^{3}$ Cito Perlin (2002), Strobel (2008), Quadros (2004), Sá (2010) e outros.

${ }^{4} \mathrm{O}$ Decreto 5626/2005, considera-se deficiência auditiva a perda bilateral, parcial ou total, de quarenta e um decibéis $(\mathrm{dB})$ ou mais, aferida por audiograma nas frequências de $500 \mathrm{~Hz}$, $1.000 \mathrm{~Hz}, 2.000 \mathrm{~Hz}$ e $3.000 \mathrm{~Hz}$ (BRASIL, 2005)
} 


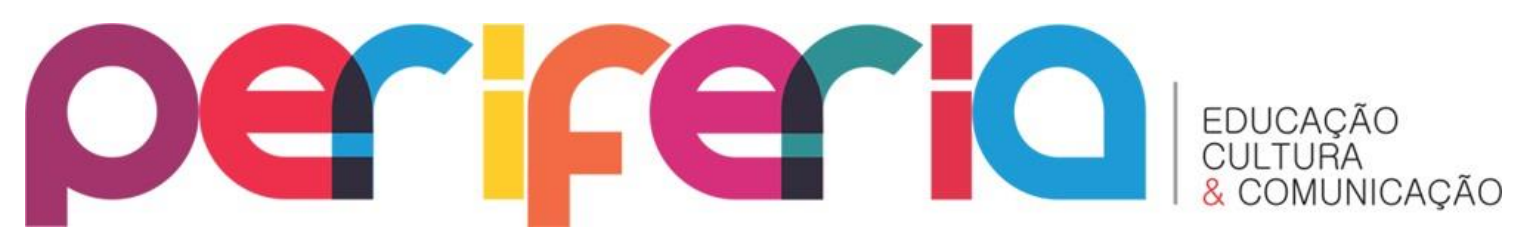

auditivos ou não, que compreendem o mundo, especialmente, por meio da leitura labial ou pelo uso dos poucos resíduos auditivos que possuem.

Essas formas de comunicação, entretanto, não os impede de viver em sociedade e interagir com outros sujeitos, seja ele ouvinte ou surdo (sinalizador ou oralizado). No processo de aquisição da língua de sinais, não se resume apenas no ato de aprender a sinalizar, mas também de vários fatores que implicam essa aprendizagem desde na infância. Os fatores podem ser ocasionados pela não aceitação da família pelo uso da Libras; falta de conhecimento da importância da língua de sinais na primeira infância pelo sujeito surdo e pela família; a falta de fluência dos profissionais da educação (professores da sala regular e Atendimento Educacional Especializado); os desafios enfrentados pelos surdos na sociedade, majoritariamente ouvintes e outros que aqui poderíamos enumerar.

Esses fatores podem refletir positivamente ou negativamente na opção pela língua de instrução e pelo desenvolvimento cognitivo desse sujeito na sociedade e na escola. Nesse sentido, o objetivo do estudo foi analisar o perfil histórico e cognitivo das pessoas surdas que implicam nos processos de aprendizagem que envolveram a aquisição da Libras de alunos surdos; e identificar experiências e fatos emocionais ocorridos no processo de aprendizagem da Língua de sinais por estudantes surdos durante seu processo de escolarização.

\section{METODOLOGIA}

A pesquisa se deu por meio da abordagem qualitativa do tipo descritivo-analítico. Este estudo teve como participantes cinco estudantes surdos universitários, que assinaram o Termo livre e esclarecido de consentimento e que se identificaram como surdos, usuários da Libras como forma de comunicação, considerados um grupo social, cultural e linguístico diferenciado, matriculados nos cursos de graduação da Universidade Federal do Pará - UFPA e Universidade Federal do Oeste do Pará - UFOPA. 


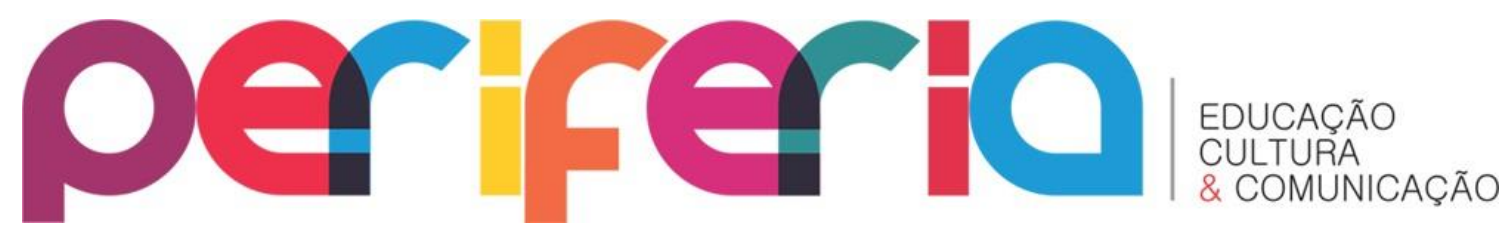

Na UFPA, no período de 2011 à 2013 foram matriculados dois alunos Surdos, sendo 1 (um) estudante no Instituto de Letras e Comunicação, Campus Belém/Guamá, do curso de graduação Letras - Libras/LP-L2; e um no Campus de Abaetetuba, na faculdade de Pedagogia. Na UFOPA foram matriculados três estudantes Surdos no curso de Pedagogia, localizados no município de Santarém/PA.

Os universitários surdos encontravam-se na faixa etária de 15 a 29 anos. Vale ressaltar que os jovens foram identificados por pseudônimos criados e justificados pelos próprios sujeitos da pesquisa, a considerar: Docinho, Miriti, Manauara, Tapajoara e Muiraquitã.

Para atingir os objetivos foram necessários para a coleta de dados a seguinte técnica: questionário semi-aberto. O questionário semi-aberto é aquele que consiste em um conjunto de questões pré-elaboradas, sistemáticas e sequencialmente dispostas em itens que constituem o tema da pesquisa. É uma interlocução planejada (CHIZZOTTI, 2006) que tem como foco as dimensões da pesquisa.

A pesquisa aconteceu com o uso de filmagem e de forma individualizada, uma vez que os sujeitos surdos estão matriculados em faculdades e municípios diferentes. O encontro com cada um dos sujeitos exigiu a participação de intérprete de Libras no processo de comunicação.

$\mathrm{Na}$ sequência, as informações foram tratadas por meio da análise de conteúdo por categorização temática ou semântica (BARDIN, 2011). Para a autora, classificar elementos em categorias significa impor a investigação de que cada um que faz parte de uma categoria tem algo em comum com os outros.

\section{O PERFIL HISTORICOCOGNITIVO DOS SUJEITOS SURDOS}

O perfil historicocognitivo dos estudantes surdos nos proporcionou compreender o lugar de onde esses sujeitos sinalizam. Nesse sentido, o "lugar", que aqui falamos não se resume a espaço, mas em substratos 


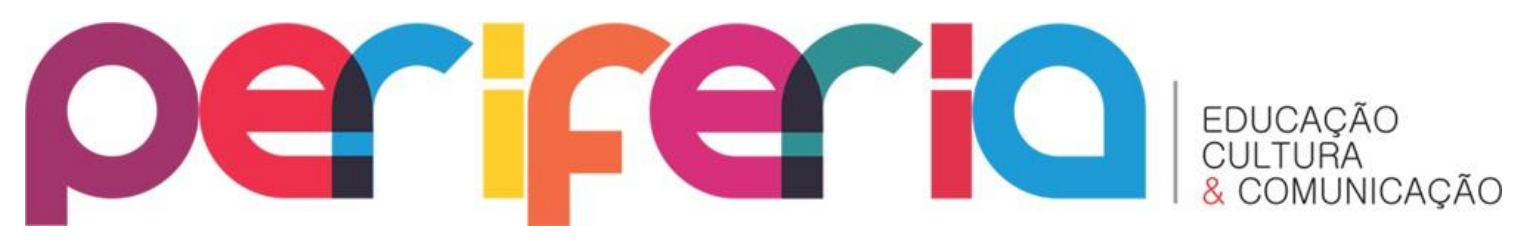

envolvidos de relações sociais, experiências vivenciadas, descobertas, sentimentos, e em formas de aprendizagens. Todas elas relacionadas à condição de ser surdo.

Dos cinco sujeitos entrevistados, três possuem surdez adquirida bilateral profunda/severa ou severa/severa (Tapajoara, Muiraquitã e Docinho) e dois possuem surdez congênita bilateral profunda (Manauara, e Miriti), isto é, os dois últimos nasceram surdos. A surdez adquirida de Tapajoara, Muiraquitã e Docinho foram resultantes das doenças rubéola e meningite acometidas durante a infância. Eles perderam a audição, respectivamente, entre dez meses e oito anos de idade e não sabiam fazer uso da Língua Portuguesa escrita. Tapajoara e Docinho tiveram contato com a Língua Portuguesa oral, mas, depois do contato com a Língua de Sinais fizeram a opção de conhecê-la melhor e usá-la. Por outro lado Manauara e Miriti, não tiveram nenhuma forma de memória auditiva pelo fato de terem nascido surdos.

Sobre as doenças que acometeram três dos sujeitos surdos na infância, Lane (1992) destaca que a causa mais comum da surdez nos "primeiros anos de vida da criança é a meningite, uma doença viral [...]. Uma das sequelas dessa doença é o crescimento ósseo que ocorre no ouvido interno durante os seis meses seguintes". Nesse sentido, o contato imediato com a Língua de Sinais seria necessário, e, quando bebê, deveria ocorrer a estimulação precoce. Para o autor,

Quanto mais tarde for a idade em que a criança assimila a Língua de Sinais, menor será a sua capacidade. As crianças Surdas congênitas e privadas da Língua durante a infância tem mais dificuldade de aprender posteriormente a Língua de Sinais do que as crianças ouvintes (LANE, 1992, p.206).

Essa realidade foi vivenciada por Miriti, Manauara e Docinho, os quais aprenderam a Língua de Sinais no período da adolescência para a juventude. Os três já estavam no final do Ensino Fundamental e início do Ensino Médio, quando aprenderam, de fato, a Libras. No que diz respeito à privação da 


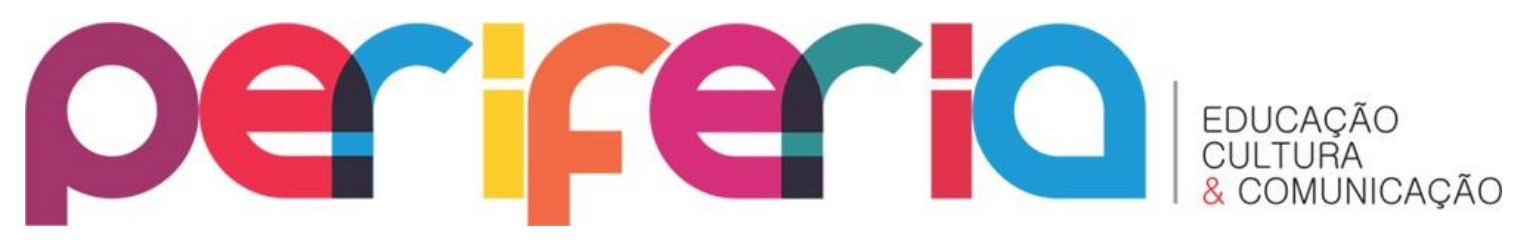

aprendizagem, esta se deu por conta da preocupação da família, em ocupar o tempo dos filhos surdos no processo de oralização/treino da fala.

Por meio do questionário semi-aberto foi possível chegarmos ao mapa mental do perfil histórico e cognitivo dos sujeitos surdos, que trouxe características significativas acerca de cada um. De acordo com a imagem 1 os pontos de destaque do perfil histórico e cognitivo dos sujeitos foram identificados como: 1) Reações da descoberta da Surdez; e 2) A aprendizagem da Língua Brasileira de Sinais - Libras. Esse perfil está organizado nesses dois elementos de destaque e suas manifestações marcadas por relações sociais com ouvintes e surdos; Experiências vividas seja na família, seja na escola; Sentimentos (raiva, felicidade, orgulho, tristeza); descobertas relacionadas a sua cultura e língua; e ainda o seu desenvolvimento cognitivo.

A construção histórica de cada sujeito perpassou pelas lembranças vinculadas às memórias da infância, que proporcionaram a descobrir as reações, encobertos por sentimentos negativos e positivos pelos próprios sujeitos e também pela família, a partir da ótica dos interlocutores surdos.

A construção cognitiva se relaciona diretamente pela aprendizagem da Língua de Sinais, adquirida por meio do contato com as comunidades Surdas e ainda na escola, no final do primeiro nível de escolarização (Educação Básica). Nesse sentido, a aprendizagem em Libras provocou no sujeito surdo sentimentos positivos ao fazer uso dela, sendo esta a língua mais usual dentro do grupo aqui estudado. As línguas utilizadas por eles se aproximam do bilinguismo, uma vez que fazem uso com frequência da Libras como primeira língua, e da Língua Portuguesa escrita como segunda língua.

Vejamos o resumo dessas ideias apresentadas no mapa mental, que organiza as análises do perfil histórico e cognitivo dos universitários de cultua surda, sujeitos deste estudo: 


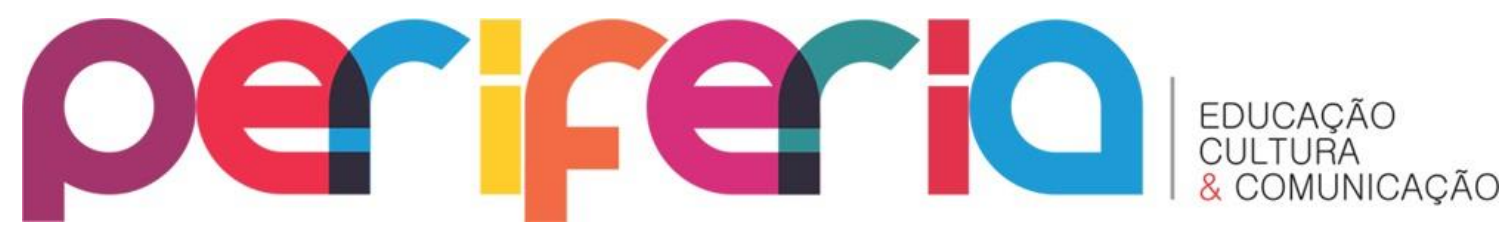

Imagem 1: Perfil histórico e cognitivo dos sujeitos surdos

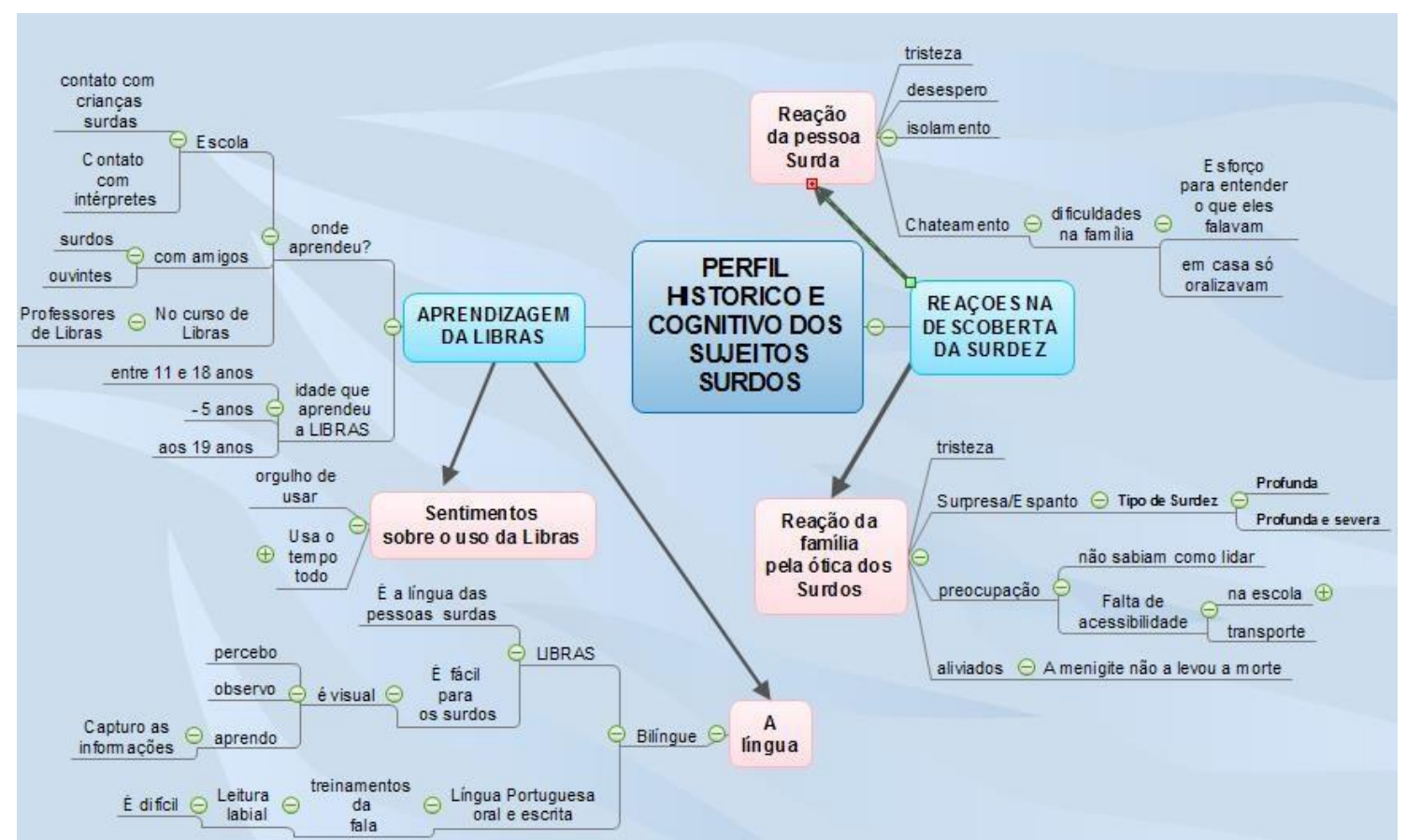

Fonte: A autora (2015). Uso do programa computacional Edraw mind map.

\section{REAÇÕES DA DESCOBERTA DA SURDEZ}

As interlocuções dos sujeitos surdos que impulsionaram as reações advindas da descoberta da surdez foram organizadas em dois momentos resultantes das sinalizações dos entrevistados: As reações do sujeito surdo; e, A reação da família pela ótica do Sujeito Surdo.

\section{a) As reações do sujeito surdo}

A descoberta do sujeito surdo, ao se deparar com sua condição de surdo, provocou nele vários sentimentos ou reações. Os mais comuns foram os sentimentos de isolamento, tristeza, desespero e chateamento. Essas reações se pautam, principalmente na observação que o sujeito surdo tinha do seu próprio lugar de pertencimento familiar, no contato com seus pais e 


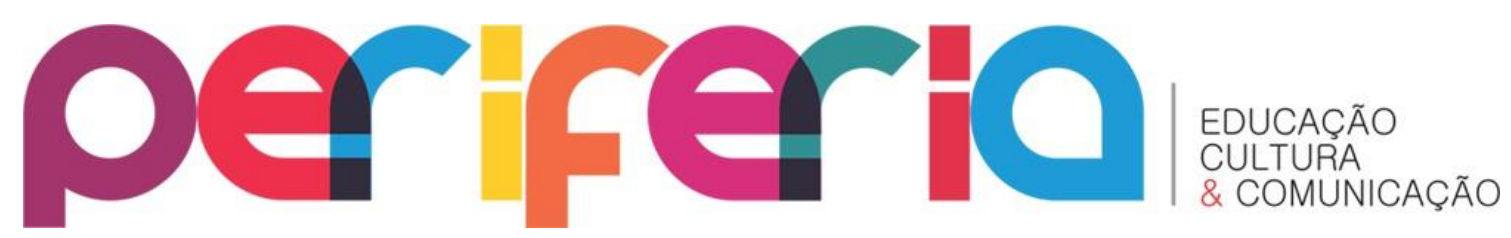

irmãos. De acordo com as falas, no espaço familiar, toda família fazia uso apenas de uma forma de comunicação: a oralização.

Nesse processo, apresentava-se para o sujeito surdo o primeiro e grande "obstáculo comunicacional", que precisava ser enfrentado no seu ambiente social mais próximo. Assim, usar de artifícios, tal como o isolamento, dentro de seu grupo parental foi a forma encontrada por muitos para não gerar tanto sofrimento. Essa realidade foi muito comum na infância de Miriti. Ele se lembra de algumas situações, e relata:

[...] dentro de casa era muito difícil [...] no início eu não sabia que era surdo [...] só olhava o movimento dos lábios da minha família, mas não entendia nada [...] foi muito difícil, quando soube que era surdo [...] eu me sentia muito sozinho e triste dentro de casa [...] (Miriti).

(Tradução: A autora, 2015).

É possível perceber nas entrelinhas do discurso de Miriti que por ele fazer parte de uma família em que os pais eram analfabetos, os pais não tinham o conhecimento e nem a preocupação em ensinar ao filho a língua natural das pessoas Surdas: a Libras. 0 movimento dos lábios da família, apresentado nas sinalizações de Miriti demonstram bem isso. Nesse sentido, Miriti, mesmo sem saber, estava envolvido por uma abordagem oralista dentro de sua casa. O fato, de a família não conhecer importância da Libras, fez com que Miriti fosse ano após anos, buscando formas de se comunicar ${ }^{5}$. Quando isso não era possível, restava-lhe o isolamento e a tristeza.

Esse obstáculo comunicacional praticado em seu lar, mesmo que sem intenção por parte de seus familiares, deixou Miriti em condições de exclusão, pois era uma pessoa com língua minoritária em seu próprio ambiente familiar. Nesse sentido, é compreensível quando nos colocamos no lugar do outro, que dentro desses espaços possam aflorar as reações de tristeza, isolamento, chateamento e desespero nas pessoas Surdas. Basta nos imaginarmos sozinhos

\footnotetext{
${ }^{5}$ As formas de se comunicar eram gestos e imitações.
} 


\section{periferio}

em um país onde não conhecemos a língua do outro. É possível, que nossa reação também seja a mesma.

Goldfeld (2002, p. 73) aponta em seus estudos que "é com base nas relações sociais que a criança aprenderá e para onde seu desenvolvimento seguirá", e que os pais têm papel fundamental nesse processo de desenvolvimento. Para confirmar isso, Vygotsky (1989), em seu livro "Os fundamentos da defectologia" explica que os filhos de Surdos se desenvolvem e aprendem mais em contato com seus pares, pois estes estão ligados aos espaços sociais onde as crianças estabelecem interações.

Desta forma, dizemos que é na infância o melhor momento da criança Surda aprender a Língua de Sinais. Mas, para isso, demanda que a família possa também interagir por meio dessa língua. Segundo Quadros e Cruz (201, p. 15), "qualquer criança adquire uma língua quando dispõe das oportunidades naturais de aquisição. " Esse não foi o caso de Miriti, pois na infância ele não aprendeu nem a Língua de Sinais e nem a Língua Portuguesa. Para se comunicar, teve que fazer uso de mímicas, pantomimas e sinais caseiros $^{6}$, muito comuns na abordagem de Comunicação Total presentes na história da educação de pessoas Surdas. ${ }^{7}$

Ainda sobre as reações do sujeito surdo, Tapajoara e Docinho relatam a tristeza e o desespero quando afirmam: "[...] eu fiquei muito triste, porque eu estava aprendendo a falar (Tapajoara); [...] minha reação foi de desespero, pois a doença que tive, a meningite atacou os nervos da minha audição, enquanto eu dormia [...] (Docinho)”. A percepção dos sujeitos em não poder conseguir captar, através do som, a fala humana, tornou-se desesperador para os casos de pessoas que durante o início da infância conseguiam escutar. Junto ao desespero veio também a preocupação com o futuro, pois não sabiam, naquele momento, como suas vidas iriam se desenhar a partir do diagnóstico da Surdez.

\footnotetext{
${ }^{6}$ Sinais caseiros é um sistema gestual restrito e limitado, criado pelo surdo para se comunicar com a sua família e amigos ouvintes, muito comum onde não conhecem a Língua de Sinais.

${ }^{7}$ Arte de exprimir sentimentos sem o uso de palavras orais. É uma representação que se configura por meio de gestos, atitudes e mímica.
} 


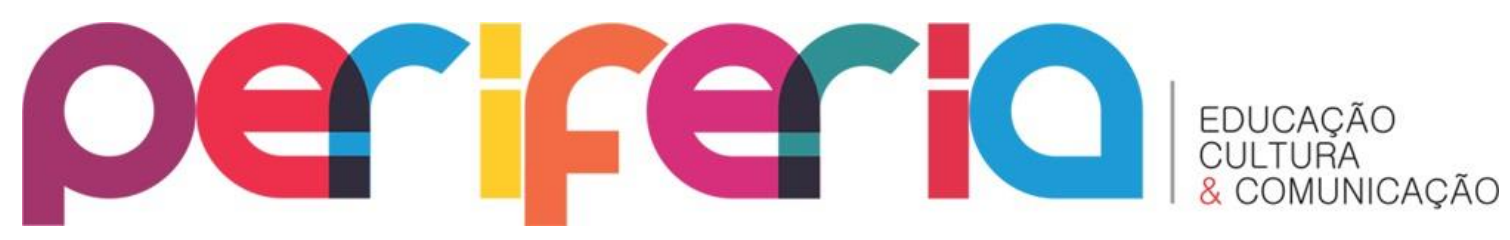

Para Fernandes e Correia (2010, p.18), a perda da audição na infância proporciona ao ser humano descobrir "novas formas de pensamento, transformando a sua concepção de mundo", e isso se dá por meio da nova aquisição simbólica que passa a se submeter. No caso de crianças ouvintes que se tornaram surdas, a nova forma simbólica que se submetem é a transformação de um modelo, visto a partir da lógica oral auditiva, para o viso-espacial.

Nessa direção, há uma série de mudanças de sentidos e sentimentos, que com a ajuda da família podem ser amenizados se for propiciado à pessoa surda a exposição a uma língua o mais cedo possível, para que assim, ela possa garantir a tempo a continuidade de seu desenvolvimento cognitivo, emocional e cultural.

Fernandes e Correia (2010) ressaltam que é importante a pessoa surda obter o conhecimento da Língua de Sinais, como uma língua nova ou mais uma possibilidade de comunicação, por considerar ideal para que ela continue se desenvolvendo social e cognitivamente, assim como para que possa ter à sua disposição os caminhos naturais de seu desenvolvimento.

Nessa via, podemos afirmar que as reações dos bebês que nascem surdos, podem se diferenciar das reações daqueles que perdem a audição depois de terem adquirido a fala. Para Muiraquitã, que perdeu a audição com dez meses, para ele é normal ser surdo, e assim observa: “[...] eu nasci sem saber falar, eu não ouvia nada, sou surdo, e acho normal ser surdo, eu tenho uma vida especial sendo surdo".

Para ele, a perda da audição, não provocou sentimentos de tristeza, pois nunca soube o que era ser ouvinte. Esse fator é de suma importância para a descoberta da identidade e cultura surda. Manauara reforça essa questão quando retrata: "[...] não sei qual era o sentimento, sempre fui surdo, não sei comparar com uma pessoa ouvinte."

Quadros e Cruz (2011) afirmam que a aquisição da língua de pessoas surdas se inicia precocemente e ocorre assim que a mesma passa a se relacionar com o seu meio, principalmente com as pessoas próximas a elas, no 


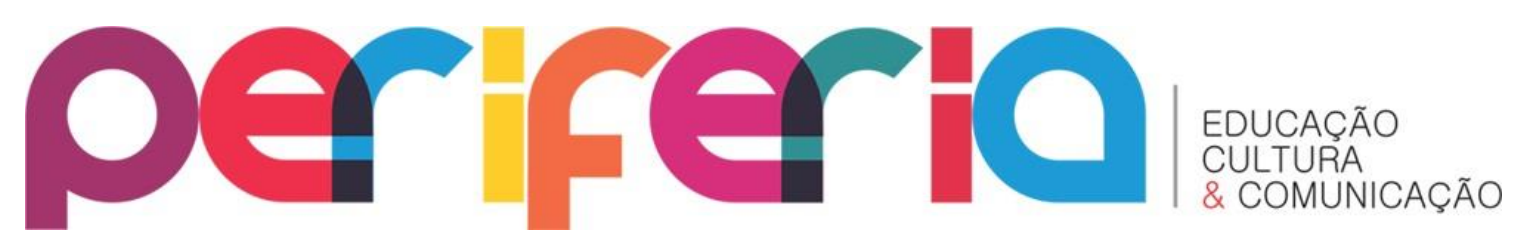

caso dos sujeitos surdos, em contato com a Língua de Sinais. Embora isso envolva processos complexos, a pessoa surda passa a sinalizar quando se encontra em situações que a levam a usar a língua proveniente de seu meio social que usam também a Língua de Sinais. A Língua de Sinais se desenvolve muito mais rápido na criança surda quando esta é filha de pais também surdos, pois a aquisição dessa língua acontecerá naturalmente, tendo em vista que é própria de sua cultura, portanto flui de forma muito mais rápida do que a Língua Portuguesa oral, oriunda de pessoas de cultura ouvinte.

\section{b) Reações da família pela ótica dos sujeitos surdos}

A partir dos relatos dos sujeitos surdos foi possível mapear também as reações da família, quando descobriram que o filho era surdo, o que se deu por meio das sinalizações dos sujeitos entrevistados. As reações da família, observadas por eles, levaram a um trajeto de sentimentos significantes, tais como:

Imagem 2: Trajeto de sentimentos significantes

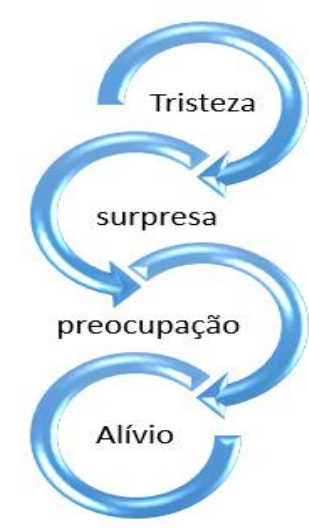

Fonte: A autora (2016).

De acordo com os sujeitos surdos, a tristeza foi o primeiro sentimento que aflorou nos pais quando souberam que os filhos eram surdos ou que adquiriram a Surdez. Sobre essa questão, Miriti diz que seus pais não sabiam 


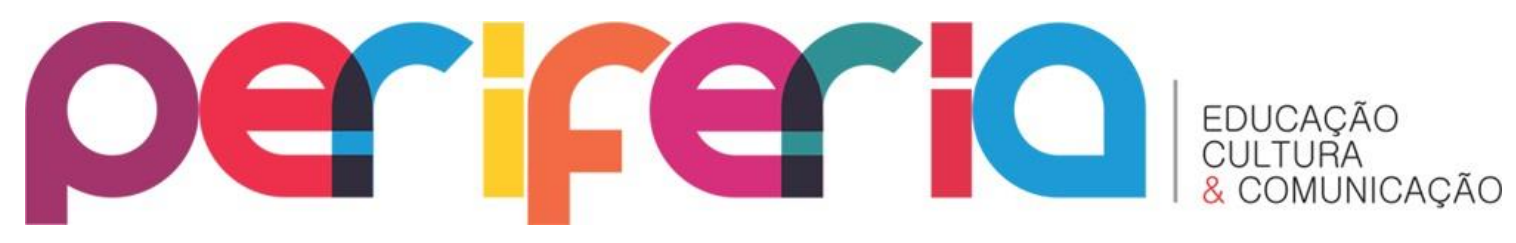

que ele era surdo na primeira infância e assim relembra: "Meus pais não sabiam que eu era surdo. Quando descobriram, ficaram tristes. Me chamavam para conversar, mas usavam mímica [...] Eu sentia que eles ficavam tristes (Miriti) ".

Quando esperam uma criança, muitos pais criam a expectativa da chegada de uma criança "normal", ou seja, que tenha como padrão a perfeição física e estética. Mas, a quando o bebê nasce e foge a esse padrão, a primeira reação da família é aglomerado de sentimentos e questionamentos revestidos de tristeza, medo e culpa.

0 medo está em não saber lidar com o filho, somado à possibilidade de serem vítimas de preconceito e discriminação. Essas situações permitem que o sujeito surdo possa perceber na figura de seus pais o cuidado exacerbado, a proteção e o sentimento de "culpa". Esse sentimento faz com que os pais se questionem acerca das motivações que levaram o filho nascerem com a Surdez ou a adquirirem.

Tal sentimento também demonstra que o primeiro momento da descoberta da Surdez do filho é considerado como um "momento do luto", envolto pela tristeza. É luto, no sentido de afirmar que os pais, no primeiro momento, não conseguem aceitar a condição do filho e todas as barreiras que ele e a própria família possam enfrentar, principalmente quando esta não está envolvida no ambiente linguístico que tem como primeira Língua a Libras.

Muiraquitã e Manauara ressaltam que seus pais ficaram tristes, mas também surpresos com o tipo de surdez que ele apresentava: "Meus pais ficaram surpresos e espantados com a surdez que eu apresentava (Muiraquitã) "; “[...] Meus Pais ficaram muito tristes e surpresos (Manauara) ". A surpresa é o segundo momento no instante da descoberta, pois é quando os pais se deparam com o grau da perda auditiva e o que isso traz como implicação na comunicação dos filhos. Aliada a essa descoberta está a preocupação.

A preocupação está relacionada ao fato dos filhos terem percebido que os pais, naquela época, não sabiam lidar com o filho surdo ou com o tipo de surdez que ele apresentava. Somado a isso, havia ainda a preocupação com a 


\section{periferio}

reação das pessoas com seus filhos no convívio social. Esse terceiro momento é marcado pelo desespero.

Nas representações de Miriti e Tapajoara percebemos que a preocupação maior dos pais está na falta de acessibilidade de comunicação nos espaços públicos e nos transportes. Na maioria desses lugares ainda é comum as pessoas desconhecerem a Libras, o que os torna em espaços considerados de estorvos comunicacionais. Nesses ambientes é comum fazerem o uso de mímicas para com as pessoas surdas. Sobre essas reações e sentimentos, os sujeitos relatam:

[...] A minha família não sabia Libras, [...] também se preocupavam comigo, quando eu pegava o ônibus, pois as pessoas não sabem Libras (Miriti).

Meus pais ficaram muito preocupados [...] Não sabiam como lidar com a situação (Tapajoara).

(Tradução: A autora, 2015).

De acordo com a Lei $N^{\circ} 10.436$ de 2002 e o Decreto $N^{\circ} 5.626$ de 2005, se fazem necessários a difusão da Língua Brasileira de Sinais como forma de garantia de acessibilidade de comunicação para as pessoas surdas em todos os espaços. A Lei $N^{\circ} 10.098$ de 2000, que trata também da acessibilidade, reforça essa questão. Contudo, apesar dos avanços da garantia legal, ainda é preciso avançar nas ações e tomadas de decisões para que essa acessibilidade aconteça de fato nos espaços públicos, seja nas escolas, ônibus ou em outros espaços, inclusive na própria família.

A quarta reação é o sentimento de alívio. Para alguns pais, na visão dos sujeitos surdos, a perda da audição representaria um obstáculo, mas ao mesmo tempo um sentimento de vitória, por perceberem que os filhos estão vivos e com saúde. 0 exemplo disso foi o caso da família de Docinho que, apesar de ter ocorrido a tristeza, houve também o alívio. Docinho perdeu a audição aos oito $\operatorname{anos}^{8}$ de idade, acometido por meningite quando dormia. Sabemos que a meningite, se não for logo diagnosticada, pode levar a óbito.

\footnotetext{
${ }^{8}$ Com oito anos Docinho já falava e estava aprendendo a ler e escrever.
} 


\section{periferio}

Nesse sentido, os pais tinham ciência de que isso poderia resultar em alguma sequela ou na perda do filho. Sobre essa questão, Docinho relata: "Meus pais tiveram a reação de tristeza, mas também ficaram aliviados porque o meu caso relacionado à Meningite poderia ter me levado à morte."

Apesar de todas essas reações ocorridas quando os sujeitos surdos ainda eram crianças, atualmente eles conseguem perceber que seus pais passaram a compreender que eles seriam pessoas "capazes e normais". Dos sujeitos entrevistados, apenas Muiraquitã relatou que sua família durante muito tempo o viu com a representação de "pessoa deficiente". Ele declara:

No passado era difícil, porque minha família pensava que eu era deficiente e que eu não poderia tomar decisões em minha vida. Foi preciso eu me impor para eu ter autonomia. Agora é mais fácil. Eu já me comunico com minha família. Eu ensinei alguns sinais para a minha mãe e meus irmãos, o que facilitou a comunicação em casa. (Muiraquitã).

(Tradução: A autora, 2015).

Sobre esse recorte, Lopes (2013) ressalta que muitas famílias e professores ouvintes exigem que a criança surda utilize apenas a modalidade oral para se comunicar. Pesquisas da autora apontam que as famílias dessas crianças acreditavam, de forma ingênua, que havia possibilidade de seus filhos se tornarem ouvintes pela oralização.

Por isso, muitos sujeitos surdos passaram boa parte de suas vidas tentando os treinamentos da fala, os quais exigiam muitos esforços e desgaste físico, emocional e cognitivo. Ao tratar dessa questão, Docinho relembra que hoje ela consegue se comunicar com pessoas surdas e ouvintes, mas ressalta que: "para eu falar (continuar falando"), tive que treinar muito. Foi muito difícil fazer leitura labial. "

A deficiência retratada pelos pais, na ótica dos sujeitos surdos, em especial Muiraquitã, revela que ainda está impregnada na sociedade a

\footnotetext{
${ }^{9}$ Relembramos que Docinho perdeu a audição no período pós-lingual. Isso significa que ela tem memória auditiva e a prática da oralização fez com que ela não esquecesse da pronúncia das palavras.
} 


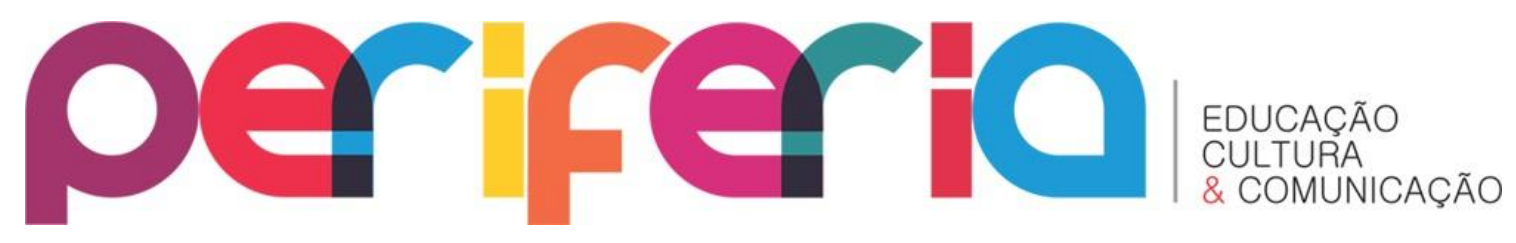

representação de que as pessoas surdas são incapazes de estudar e viver em sociedade, portanto que estas são dependentes dos ouvintes. Na contramão, Goldfeld (2002) defende a ideia de que todos podem estudar e agir a favor da comunidade de surdos, de sua língua e de sua cultura própria, no sentido de estimularem e divulgarem a Língua Brasileira de Sinais. Ter uma deficiência, atualmente, não é mais limitador de escolarização. Cada grupo pode se adequar de variadas formas na escola. Por outro lado, a escola também precisa se adequar às necessidades individuais de cada aluno, de cada cultura.

No caso das pessoas surdas, a cultura linguística não é apenas aquela caracterizada, unicamente, pelo uso da Libras, que se diferencia da cultura de ouvintes e falantes, mas também aquelas que são caracterizadas por pessoas surdas que oralizam e fazem uso da Libras para se comunicar com sujeitos surdos e ouvintes, o que possibilita pessoas surdas e ouvintes a desenvolverem maneiras de ser, pensar e agir de formas muito diferentes. Nesse interim, cabe à escola buscar caminhos metodológicos e adaptações para esse processo.

\section{A APRENDIZAGEM DA LIBRAS}

Ainda na Identificação do perfil, os sujeitos surdos relacionam por meio de suas lembranças as experiências cognitivas acerca de sua aprendizagem da Língua de Sinais. As questões levantadas nos ajudaram a compreender como, onde e de que forma essa aprendizagem ocorreu.

A Libras foi apresentada à Manauara, Tapajoara e Miriti por meio da escola. Muiraquitã, por sua vez, afirmou que aprendeu a LS nas ruas, em contato com os amigos surdos e ouvintes fluentes em Língua de Sinais, o que ocorreu a partir dos onze anos de idade. Nessa faixa etária Docinho também começou a aprender a Libras, mas, diferente dos demais, essa iniciação se deu por meio de sua participação no curso de Libras, com os professores dessa língua. 


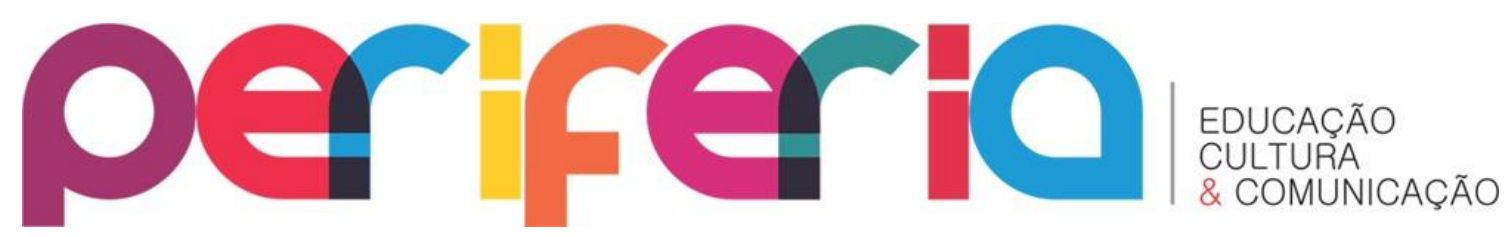

Entre os entrevistados, o estudante surdo que iniciou tardiamente a aprendizagem em Libras foi Miriti, o qual passou a ter contato com a Língua de Sinais por volta dos dezenove anos de idade. Nessa idade, Miriti já se encontrava no Ensino Médio. Antes disso, sua forma de comunicação era a mímica, muito usual entre sua família. No que se refere ao fato de ter nascido surdo, nos chamou atenção este relato, no qual ele comenta ter enfrentado barreiras de comunicação em casa:

Meus pais me chamavam para conversar, mas usavam mímica, pois eles não sabiam libras. Me ajudaram muito pouco na infância com relação ao uso da Libras, era só mímica, e senti isso como problema. Meus pais escreviam no papel o que eles queriam saber, mas eu não conhecia direito, eles me ensinavam a escrita da Língua Portuguesa e ficavam preocupados porque eu não entendia nada. [...] Passaram os anos eu sempre esperava um professor, e que meus pais me explicassem em Libras, mas nada acontecia. Ficava sempre muito sozinho, foi um problema. Anos após anos os professores só explicavam, e eu copiava as palavras, mas sem entender o seu significado. Eu perguntava e ninguém me entendia. A cada ano só tirava nota baixa e reprovava (Miriti).

(Tradução: A autora, 2015).

Para esse estudante surdo, as dificuldades foram imensas. Miriti, está no grupo, dentre muitos surdos, que não tiveram o acesso à Libras na idade certa. Segundo Lodi, Harrison e Campos (2014, p.37), o que ocorreu nesse período foi o "desenvolvimento de uma comunicação gestual caseira utilizada para fins de satisfação das necessidades e relatos dos acontecimentos familiares". Dessa forma, a Libras é concebida como uma língua menor para a família que desconhece a Língua de Sinais, e isso reflete a posteriori, no desenvolvimento do próprio sujeito surdo.

As sinalizações anunciadas pelos sujeitos pesquisados demonstram que houve uma aprendizagem tardia da Língua de Sinais. A família esteve longe do processo de construção dessa comunicação, devido à falta de orientação, o que ocorre com a maioria dos brasileiros em situações como essas, e implica 


\section{periferio}

no reconhecimento tardio da necessidade do filho surdo aprender a Libras na primeira infância.

Desta forma, é comum nos registros da maioria dos estudantes surdos que a aprendizagem da Libras ocorra na adolescência, quando em contato com amigos surdos e colegas de escola, que já conheciam a Libras ou nos cursos dessa língua. A família apareceu muito pouco nesse cenário como suporte para o filho na aprendizagem da Língua de Sinais, assim como foram raríssimas as famílias que buscaram conhecer a Libras para se comunicarem com seus filhos surdos. Essa busca sempre partiu do próprio sujeito surdo, em contato com as comunidades surdas.

No que diz respeito ainda ao uso da Libras na escola pelos sujeitos, apenas Tapajoara teve a oportunidade de ter o contato com a estimulação precoce na Educação Infantil. Manauara e Muiraquitã começaram esse processo a partir do $6^{\circ}$ ano. Já Docinho e Miriti iniciaram o contato e aprofundamento da Língua Brasileira de Sinais no Ensino Médio.

Para Sá (2011, p.57), infelizmente, não há uma proposta que, de fato, valorize a comunicação natural das pessoas surdas; "o que tem sido oferecido aos surdos são apenas propostas alternativas ou complementares, e uma política inclusiva". A Política Nacional de Educação Especial na Perspectiva da Inclusão (2008) e ainda o Decreto $N^{\circ} 7.611 / 2011$ estabelecem que para atender esse modelo de escola inclusiva, o chamado Atendimento Educacional Especializado (AEE), resolveria o problema com práticas e atividades que garantiriam a complementação da comunicação.

No entanto, como afirma Sá (2011), o AEE não dá e não dará conta de atender o verdadeiro propósito da comunidade surda e sua forma de comunicação. A autora ainda destaca que isso só será possível se os sujeitos surdos estiverem imersos em uma comunidade sinalizadora.

Talvez a forma como esse processo venha se dando, não esteja sendo o suficiente para garantir que os mesmos possam alcançar fluência em Língua de Sinais o mais cedo possível. Nesse sentido, há de se considerar a proposta de consolidação das classes bilíngues nas escolas e de ambientes propícios e 


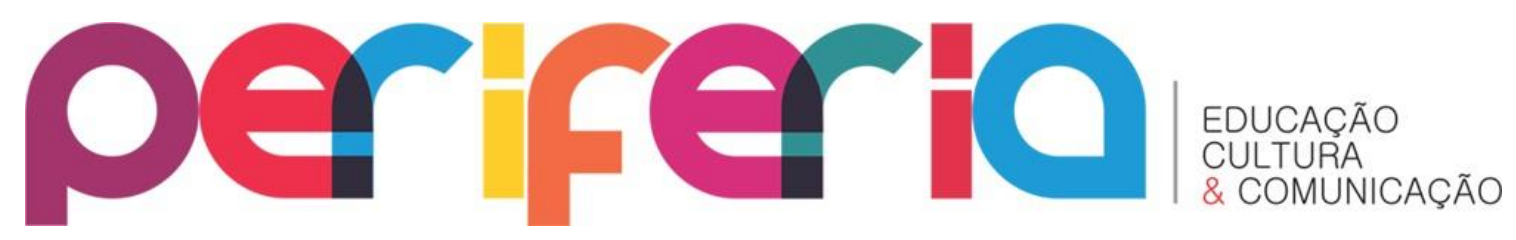

naturais para a apreensão da Libras por esse grupo (SÀ, 2011). Além disso, há necessidade de divulgar junto às famílias, o mais cedo possível, a importância da Língua de Sinais como forma de comunicação para crianças surdas nos primeiros anos de vida, como meio para a estimulação precoce.

Assim sendo, a construção cognitiva da Libras foi fundamental para o desenvolvimento dos sujeitos surdos. A aprendizagem da Libras está envolvida por sentimentos sobre o uso dessa língua, dentre elas o sentimento de orgulho de usar a libras, como sua Língua de instrução.

\section{A LÍNGUA DE INSTRUÇÃO: APROXIMAÇÕES DO BILINGUISMO}

No contexto dos discursos, os sujeitos surdos se aproximam do bilinguismo, pois usam a Libras como primeira língua e a Língua Portuguesa escrita como segunda Língua, no entanto, a apropriação da segunda língua ainda é um obstáculo para os sujeitos surdos. Consideramos como segunda língua para os sujeitos surdos a escrita da LP ou a forma oral dessa língua, esta última não é descartada para os sujeitos que assim o desejarem se apropriar, como afirma o Decreto 5.626 de 2005, art. $16 .^{10}$

Ressaltamos que, para os integrantes deste estudo, todos os alunos que aprenderam a oralizar admitiram, que em alguns momentos, fazem uso dessa modalidade diante da necessidade de se comunicar com pessoas ouvintes que não conhecem Libras. Ressaltamos que três sujeitos surdos passaram por esse processo de treinamento fonoarticulatório não negam a importância de conhecer a Língua Portuguesa, tanto escrita como a oral. Nessa mesma direção, a estudante Docinho, a qual perdeu a audição no período pós lingual, reforça que possui até hoje a memória auditiva e que ainda consegue fazer boa leitura labial, assim como consegue escrever a Língua Portuguesa,

10 O Decreto 5626 de 2005 destaca no artigo 16 que a modalidade oral da Língua Portuguesa, na educação básica, "deve ser ofertada aos alunos surdos ou com deficiência auditiva, preferencialmente em turno distinto ao da escolarização, por meio de ações integradas entre as áreas da saúde e da educação, resguardado o direito de opção da família ou do próprio aluno por essa modalidade" (BRASIL, 2005, grifo nosso) 


\section{periferio}

sem muitos entraves. Para ela, tanto a Libras quanto a Língua Portuguesa foram importante para sua formação e afirma: "ambas são importantes para a minha formação social, porque eu posso me comunicar com surdos e ouvintes."

Entretanto, todos dizem que a melhor língua para a pessoa surda se comunicar é a Libras, porque é mais visual (Muiraquitã) dentro da comunidade surda. Sendo assim, a cultura surda se manifesta como identidade em cada um dos sujeitos que consegue perceber a importância da Libras em suas vidas como forma de comunicação. É a Língua que abraça sua forma de ver e apreender o mundo.

Os sentimentos de negação pela Língua Portuguesa oral é perceptível no grupo de pessoas surdas, que fazem uso e reconhecem a importância da Libras ou que nasceram surdos. Os depoimentos revelam que a Língua Portuguesa oral para os surdos é uma língua sem vida. Os sujeitos surdos apresentam grandes dificuldades de compreensão em relação ao que as pessoas ouvintes falam. O processo de captação da informação é mais difícil do que em Libras. Sobre essa questão, eles esclarecem:

Eu não uso a Língua Portuguesa oral, porque eu gosto de Libras [...] a Língua Portuguesa é diferente da Libras [...] $\mathrm{Na}$ Língua Portuguesa as pessoas falam e eu não entendo nada porque eu sou surdo e com a Libras eu capto a informação e aprendem melhor. A Libras é ótima e muito importante para os Surdos. (Miriti)

A Libras, tem a comunicação mais visual, então, para nós surdos, é mais fácil de se comunicar. Eu falo também um pouco e faço uso da leitura labial, mas eu prefiro a Libras (Muiraquitã).

A Libras é mais fácil para se comunicar com surdos e ouvintes fluentes em Libras (Tapajoara).

(Tradução: A autora, 2015)

As sinalizações dos sujeitos surdos são merecedoras de reflexões e redefinição de sua forma de pensar ao se tratar do método oral como a melhor opção para os sujeitos surdos se desenvolverem. Compreender a Língua de Sinais como forma de comunicação para eles é, sem dúvida, 


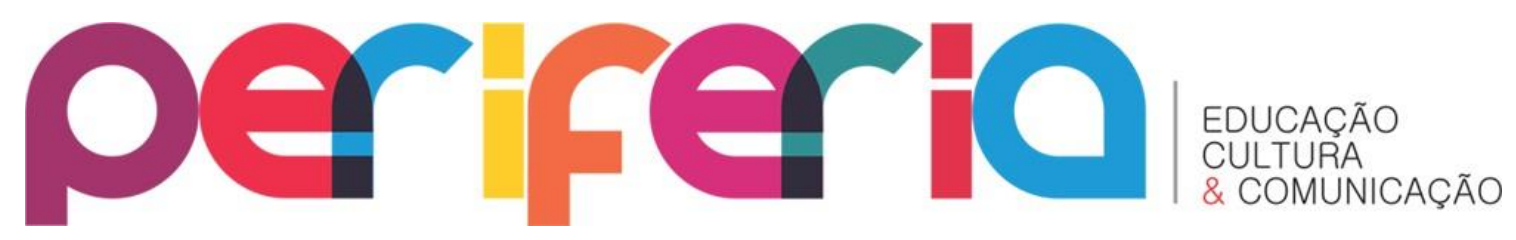

perceber sua forma de aprender e apreender o mundo de forma mais acessível.

Nos estudos de Stokoe (1960) vimos que a Língua de Sinais apresenta as mesmas restrições que ocorrem com a língua oralizada. Contudo, por ser uma modalidade viso-espacial, torna-se para o sujeito Surdo a forma mais rápida de aprender. Sobre essa questão, Quadros e Cruz (2011) comentam que as crianças surdas, filhas de pais Surdos, adquirem as regras de sua gramática de forma similar às crianças ouvintes.

Com essa aquisição, construída ao longo da trajetória e de sua relação com o meio, os sujeitos surdos puderam pensar em planos futuros, projetos de vida, lutar pelos seus direitos e de seus pares e garantir que sua língua seja divulgada, conhecida e usada, tanto por sujeitos Surdos como por ouvintes.

\section{CONSIDERAÇÕES FINAIS}

Ao finalizar este estudo, nos deparamos com representações que marcaram experiências de vida de pessoas surdas, de forma negativa e positiva, ao longo de todo o percurso escolar desses estudantes. Elas revelaram projetos de vida que compactuaram ou serviram de justificativa para apontar escolhas futuras, e a maior delas foi à docência.

Vale ressaltar que o percurso de suas vivências na escolarização, bem como de suas memórias do passado, revelaram variados momentos que apontaram denúncias e enfrentamentos decorrentes dos processos de exclusão. Eles acreditam e projetam uma outra história que pode ser construída com a possibilidade da presença de pessoas surdas na reconstrução de uma nova escola para elas, com o objetivo de fazer a diferença, seja na escola dita inclusiva, seja na escola/classe específica para pessoas surdas.

Trata-se, portanto, de uma outra geração de educadores surdos que desejam fazer a mudança na escola para seus pares. Os depoimentos de cada estudante fazem refletir sobre a aprendizagem que esse grupo obteve no 


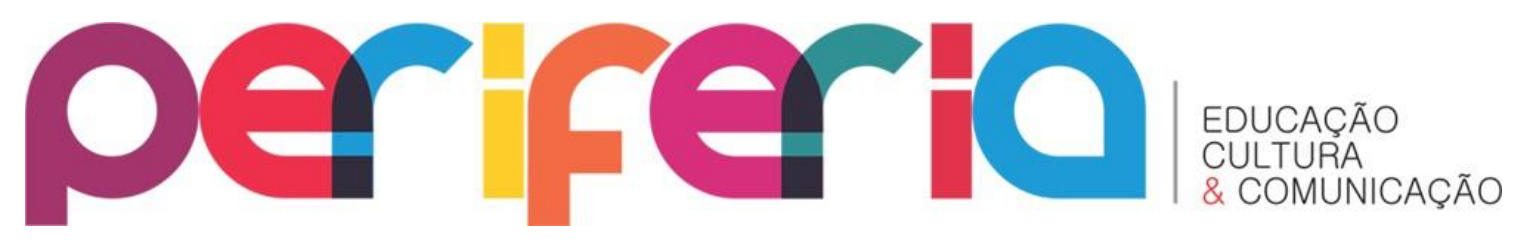

momento em que eles nos permitiram adentrar em suas histórias, vivências, sofrimentos, mas também às conquistas e esperanças.

Este estudo nos fez viajar no tempo e na história da escolarização de cada estudante Surdo pesquisado e, acima de tudo, nos colocar no lugar deles. Isso se deu por meio de cada conjunto de sinais, cada expressão facial e cada movimento do corpo desses sujeitos. Com essas palavras podemos dizer que finalizamos a caminhada deste documento escrito; mas, com a certeza, esse estudo nos deixou com outros questionamentos sobre esse grupo social, tais como, o mercado de trabalho para surdos; o trabalho dos professores surdos nas Educação Básica e no ensino superior; a relação dos alunos ouvintes matriculados em escolas bilíngues para surdos.

No que diz respeito a aprendizagem da Libras, os sujeitos apontam variados lugares que proporcionaram esse encontro e descoberta da Língua de Sinais. Os principais espaços foram à escola, e nos cursos de Libras, quando em contato com os amigos surdos e ouvintes fluentes na Língua de Sinais.

As interlocuções anunciadas nos perfis dos sujeitos pesquisados demonstram uma aprendizagem tardia da Língua de Sinais. A família esteve longe desse processo de construção pois, como posto acima, a maioria deles buscou a aprendizagem da Libras em outros ambientes, menos na própria casa com o apoio dos pais. Nesse sentido, a família ainda é o espaço que precisa de orientação, no que diz respeito à chegada de um filho com surdez. Essa ação poderá propiciar o uso da Libras, o mais cedo possível, e assim diminuir o isolamento familiar para com os sujeitos surdos.

0 perfil dos sujeitos surdos construídos por meio de sentimentos (reações, relações, emoções negativas e positivas) e de formas de aprendizagem que se voltaram para o orgulho do uso da Língua de sinais, como identificação de uma cultura surda que percebe ao longo de suas experiências de vida familiar e escolar, que a Libras se manifesta como a melhor opção para o processo de aprendizagem na escola e nas interações entre surdo-surdo e surdo-ouvinte que conhece a língua de sinais. 0 contato com outros surdos e professores fluentes na Libras proporcionou aquisição e 


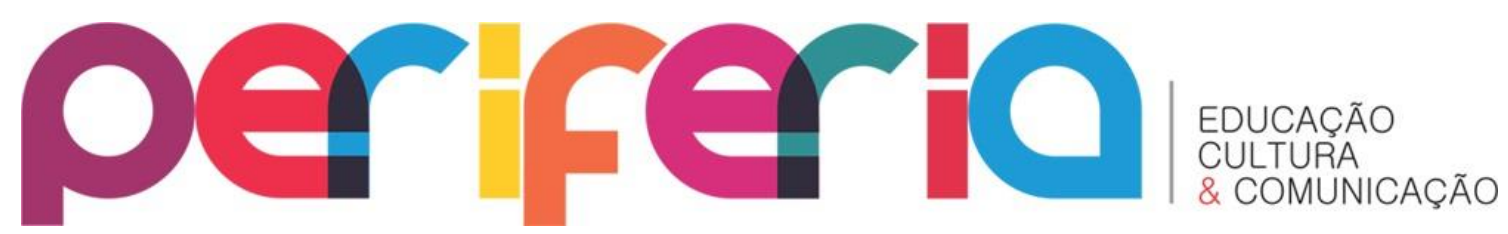

aprimoramento da língua de sinas, apontada como sua língua de instrução com aproximações do bilinguismo

\section{REFERÊNCIAS}

BARDIN, Laurence. Análise de conteúdo. Lisboa: Edições 70, 2011

BRASIL. Decreto 5.626/2005 que regulamenta a Libras e art.18 da Lei 10.098. Brasília: Congresso Nacional, 2005.

. Política Nacional de Educação Especial na Perspectiva da Inclusão.

Brasília: MEC, 2008

. Lei 7.611/2011. Regulamenta o atendimento da Educação Especial e o Atendimento Educacional Especializado. Brasília: MEC, 2005.

CHIZZOTTI, Antonio. Pesquisa em Ciencias Humanas e Sociais. 8.ed. São Paulo: Cortez, 2006.

DECLARAÇÃO MUNDIAL DE EDUCAÇÃO PARA TODOS. Jontiem: UNICEF, 1990. Disponível em http://www.unicef.org/brazil/pt/resources_10230.htm. Acesso em 02 jan 2015.

ESPANHA. Declaração de Salamanca. Necessidades Educativas Especiais. In.: Conferencia Mundial sobre NEE. Acesso em Qualidade UNESCO: Salamanca: Espanha: UNESCO, 1994.

FERNANDES, Eulália; CORREIA, Claudio Manoel de C. Bilinguismo e Surdez: A evolução dos conceitos no domínio da Linguagem. In.: FERNANDES, Eulália (org.). Surdez e bilinguismo. Porto Alegre: Mediação, 2010.

GOLDFELD, Marcia. A criança surda: linguagem e cognição numa perspectiva sócio-interacionista. $5^{a}$ ed. São Paulo: Plexus Editora, 2002.

LANE, Harlan . A Máscara da Benevolência: A comunidade surda amordaçada. (Tradução Cristina Reis). Coleção horizontes pedagógicos: Instituto Piaget, 1992.

LODI, Ana Claudia B.; HARRISON, Kathryn Marie P.; CAMPOS , Sandra Regina L. de. Letramento e surdez: Um olhar sobre as particularidades dentro do contexto educacional. In.: LODI, Ana Claudia B. (orgs.) Letramento e minorias. 7.ed. Porto Alegre: Mediação, 2014.

LOPES, Maura C. A mediação material e sígnica no processo de integração de crianças Surdas. In.: SKLIAR, Carlos. Educação e Exclusão: abordagens 


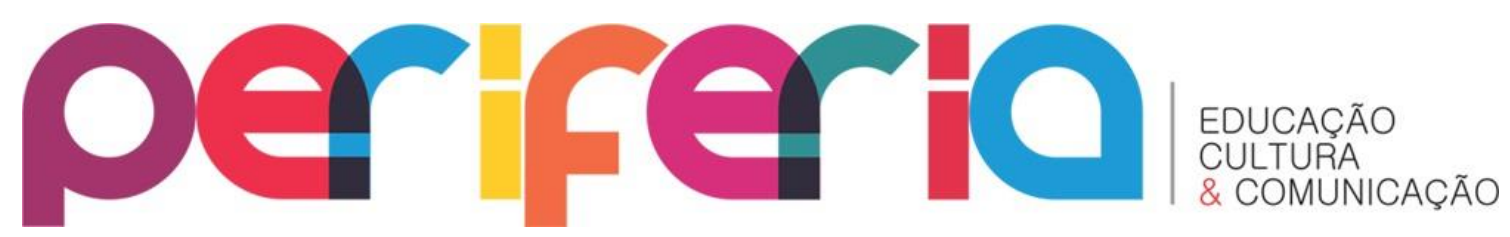

socioantropológicas em educação especial. 7 ed. Porto Alegre: Medicação, 2013.

PERLIN, Gladis T.T. Identidade surda. In: SKLIAR, Carlos (org). A surdez: um olhar sobre as diferenças. Porto Alegre: Mediação, 1998.

QUADROS, Ronice M. de. KARNOPP. Lodenir B. Língua Brasileira de Sinais: Estudos linguísticos. Porto Alegre: Artmed, 2004.

QUADROS, Ronice M. de; CRUZ, Carina Rebello. Língua de Sinais: Instrumentos de avaliação. Porto Alegre: Artmed, 2011

SÁ, Nidia Limeira. Escolas e Classes de Surdos: Opção político-pedagógica Legítima. In.: SÁ, Nidia Limeira (Org.). Surdos: qual escola? Manaus: Editora Valer e Edua, 2011.

STROBEL, Karin; FERNANDES, Sueli. Aspectos Linguísticos da Língua Brasileira de Sinais. Secretaria de Estado de educação; Superintendência de Educação,Departamento de Educação Especial. Curitiba/SUED/DEE,1998

VYGOTSKY, L. S. Fundamentos de Defectologia. Obras completas, tomo 5. Habana: Pueblo y Educación. 1989 